\title{
Determination of the spatiotemporal dependence of Pseudomonas aeruginosa biofilm viability after treatment with NLC-colistin
}

This article was published in the following Dove Press journal:

International Journal of Nanomedicine

12 June 2017

Number of times this article has been viewed

\author{
Eulalia Sans-Serramitjana' \\ Marta Jorba' \\ José Luis Pedraz \\ Teresa Vinuesa' \\ Miguel Viñas' \\ 'Laboratory of Molecular \\ Microbiology and Antimicrobials, \\ Department of Pathology and \\ Experimental Therapeutics, University \\ of Barcelona, Barcelona, ${ }^{2}$ Laboratory \\ of Pharmaceutics, University of the \\ Basque Country (UPV/EHU), Centro \\ de Investigación Biomédica en Red \\ de Bioingeniería, Biomateriales y \\ Nanomedicina, Vitoria, Spain
}

Correspondence: Miguel Viñas Laboratory of Molecular Microbiology, University of Barcelona, Feixa Llarga s/n, 08907 L'Hospitalet de Llobregat, Barcelona, Spain

Tel +34934024265

Email mvinyas@ub.edu

\begin{abstract}
The emergence of colistin-resistant Pseudomonas aeruginosa in cystic fibrosis (CF) patients, particularly after long-term inhalation treatments, has been recently reported. Nanoencapsulation may enable preparations to overcome the limitations of conventional pharmaceutical forms. We have determined the time-dependent viability of $P$. aeruginos $a$ biofilms treated with both free and nanoencapsulated colistin. We also examined the relationship between the optimal anti-biofilm activity of nanostructured lipid carrier (NLC)-colistin and the structural organization of the biofilm itself. The results showed the more rapid killing of $P$. aeruginosa bacterial biofilms by NLC-colistin than by free colistin. However, the two formulations did not differ in terms of the final percentages of living and dead cells, which were higher in the inner than in the outer layers of the treated biofilms. The effective anti-biofilm activity of NLC-colistin and its faster killing effect recommend further studies of its use over free colistin in the treatment of $P$. aeruginosa infections in $\mathrm{CF}$ patients.
\end{abstract}

Keywords: cystic fibrosis, colistin sulfate, lipid nanoparticles, $P$. aeruginosa, confocal laser scanning microscopy, anti-biofilm activity

\section{Introduction}

Pseudomonas aeruginosa is a gram-negative opportunistic pathogen that frequently infects the lungs of cystic fibrosis (CF) patients in the form of chronic biofilm infections. ${ }^{1}$ The antimicrobial resistance of bacteria assuming a biofilm mode of growth poses challenges not only to host immune clearance mechanisms but also to health care settings, in the form of an increased risk of hospital-acquired infections. ${ }^{2}$ The high level of antibiotic resistance that characterizes biofilms can be attributed to their structurally heterogeneous microenvironments, some of which contain metabolically inactive cell population, ${ }^{3,4}$ as well as to the differential expression of multiple gene networks and extracellular matrix by the resident bacterial species. ${ }^{4}$

Over the last decade, increasing attention has been paid to antimicrobial peptides (AMPs) as therapeutic agents, because resistance to them is thus far rare. Moreover, these peptides are able to modulate the innate immune response. ${ }^{5-7}$ The AMP colistin is a cyclic cationic decapeptide that attacks negatively charged bacterial membranes, thereby disrupting both the outer and inner membranes of gram-negative species. ${ }^{7}$ Although the use of colistin as an antimicrobial is restricted by its high nephrotoxicity, the increasing emergence of multiresistant pathogens has renewed interest in its therapeutic potential. ${ }^{8}$ In fact, nowadays, colistin is administered to CF patients and to other patients with chronic respiratory diseases for the treatment of lung infections 
caused by $P$. aeruginosa. ${ }^{9}$ However, colistin resistance, mediated by the post-translational modification of lipopolysaccharide, has emerged, perhaps driven by the increasing clinical use of this drug. ${ }^{10,11}$ Although resistance rates are still low in many countries, the recent identification of a plasmid-borne colistin resistance gene ( $m c r-1)$ in human, animal, and environmental isolates of Enterobacteriaceae may soon lead to rapid increases in resistance on a global scale. ${ }^{12,13}$ An awareness of this threat has catalyzed the search for less toxic antimicrobials as well as the development of synthetically modified forms enabling dose reductions, longer administration intervals, and reduced systemic toxicity. An alternative is new delivery strategies, such as the use of solid lipid nanoparticles and nanostructured lipid carriers (NLCs) to deliver colistin in CF patients with $P$. aeruginosa respiratory infections. The nebulization of antimicrobials carried in lipid nanoparticles improves drug bioavailability and allows a reduced dosing frequency. ${ }^{14}$ In principle, the administration of encapsulated drugs could overcome preexisting resistance mechanisms, including the decreased uptake and increased efflux of the drug, as well as biofilm formation. ${ }^{15}$ In a previous study, we demonstrated the higher anti-biofilm activity of NLC-colistin than of free colistin in both susceptible and resistant $P$. aeruginosa strains isolated from the sputum samples of CF patients. ${ }^{16}$ As biofilms play a key role in the natural history of $P$. aeruginosa respiratory infections in $\mathrm{CF}$, the use of NLC-colistin may offer new approaches to their treatment. However, the mechanism underlying the improved efficiency of NLC-colistin in biofilm removal is unknown. ${ }^{16}$ Pamp et $\mathrm{al}^{17}$ showed that free colistin acts preferentially on bacteria with low metabolic rates; this is the case for bacteria in the deepest layers of a biofilm, as metabolic activity decreases with increasing distance from the biofilm surface. Whether the same differential response occurs with NLCcolistin has not been determined. Thus, this study explored the efficacy of NLC-colistin versus the free drug with respect to biofilm viability over time and across the different layers of the biofilm.

\section{Materials and methods}

\section{Preparation of lipid nanoparticles}

NLCs were prepared using the hot melt homogenization technique. ${ }^{18}$ The lipid core consisted of Precirol ${ }^{\circledR}$ ATO 5 (Gattefossé, Madrid, Spain) and Miglyol 812 (Sasol, Hamburg, Germany), which were mixed with colistin sulfate (Zhejiang Shenghua Biok Biology Co., Ltd., China). The temperature of the mixture was gradually increased to the melting temperature of the solid lipids. The surfactant solution was 1.3\% (w/v) Polysorbate 80 (Panreac Química, Castellar del
Vallès, Barcelona, Spain) and 0.6\% (w/v) Poloxamer 188 (BASF, Ludwigshafen, Rhineland-Palatinate, Germany). The mixture was emulsified by sonication for $15 \mathrm{~s}$ at $20 \mathrm{~W}$. The nanoparticles were recrystallized by an overnight incubation at $4{ }^{\circ} \mathrm{C}$ to stimulate particle formation. They were then washed three times by centrifugation at 2,500 rpm in Amicon centrifugal filtration units (100,000 MWCO). All prepared nanoparticles were freeze-dried with trehalose $(15 \%)$.

\section{Bacterial strain, culture conditions, and biofilm formation}

P. aeruginosa strain PA01 in $20 \mathrm{~mL}$ of Mueller-Hinton II broth cation adjusted (Becton Dickinson Diagnostic Systems, Inc., Sparks, MD, USA) was grown overnight at $37^{\circ} \mathrm{C}$ with continuous shaking at $250 \mathrm{rpm}$. The culture was then adjusted to a concentration of $1-5 \times 10^{8} \mathrm{cfu} / \mathrm{mL}$, and $200 \mu \mathrm{L}$ was used to inoculate $\mu$-Slide 8 glass bottom wells (Ibidi, cat. num. 80827, Munich, Germany). Each well was previously coated with a $0.01 \%(\mathrm{w} / \mathrm{v})$ poly-lysine hydrobromide (Sigma-Aldrich, Dorset, UK) solution to enhance bacterial cell adhesion and to prevent biofilm removal during the experiments. The slides were incubated at $37^{\circ} \mathrm{C}$ for $24 \mathrm{~h}$ to allow biofilm formation.

\section{Confocal laser scanning microscopy imaging}

Biofilms on the eight-well glass were washed once with Ringer $1 / 4$ to remove unfixed bacteria and then treated with free and NLC-colistin at a colistin concentration of $128 \mu \mathrm{g} / \mathrm{mL}$, based on previously published results. ${ }^{16}$ They were then incubated at $37^{\circ} \mathrm{C}$ for $20,30,40,60,80$, and 100 min after which they were rinsed once with Ringer $1 / 4$. To stain the biofilms, a mixture of SYTO 9 and propidium iodide prepared at a dilution ratio of $1: 2(1.5 \mu \mathrm{L}$ of SYTO 9 and $3 \mu \mathrm{L}$ of propidium iodide in $1 \mathrm{~mL}$ of Ringer $1 / 4$ ) was applied to the entire biofilm. After $30 \mathrm{~min}$ of incubation in the dark at $37^{\circ} \mathrm{C}$, the stained biofilms were washed once with Ringer $1 / 4$ to remove nonspecific staining. Fluorescence was observed using a Leica TCS-SL filter-free spectral confocal laser-scanning microscope (Leica Microsystems, Mannheim, Germany) equipped with a 488-nm argon laser, 543-nm and 633-nm He/Ne lasers (Scientific and Technological Centers, University of Barcelona, Bellvitge Campus, L'Hospitalet de LLobregat, Spain), and a $63 \times$ magnification oil immersion objective (1.4 numerical aperture). The image resolution was $1,024 \times 1,024$ pixels. All experiments were performed in duplicate. Confocal laser scanning microscopy (CLSM) images were analyzed using Image J software (National 
Institutes of health, Bethesda, MD, USA). The percentages of alive and dead bacterial cells were calculated from the total cell number.

\section{Results and discussion \\ Time-dependent killing of strain PAOI biofilms by free and NLC-colistin}

Enumeration of the viable and dead bacteria for every treatment showed an increase in bacterial death over time in the strain PAO1 biofilms (Figure 1). In the control (untreated) biofilms, most of the cells were viable, with live/dead ratios of $78.2 \%$ (green) and $21.8 \%$ (red), respectively. This result was in agreement with a previous report. ${ }^{19}$ The baseline viability was taken into account in the interpretation of the experimental data. A nonlethal effect was observed in biofilms exposed for $20 \mathrm{~min}$ to free colistin, with the proportions of living and dead bacteria almost identical to that of the control ( $\sim 80 \%$ and $20 \%$, respectively). The killing efficiency reached a maximum of $80 \%$ after $60 \mathrm{~min}$ of treatment with the free formulation. By contrast, after $20 \mathrm{~min}$ of exposure to NLC-colistin, $\sim 75 \%$ of the individual cells were dead (red fluorescence) and after 60 min of treatment almost $100 \%$, thus demonstrating the rapid killing effect of the encapsulated drug.

The results shown in Figure 1 are in good agreement with the CLSM images of the untreated and treated biofilms (Figure 2). The latter mostly stained green (Figure 2), indicating a high level of bacterial viability. After 20 and $40 \mathrm{~min}$ of exposure to NLC-colistin (Figure 2), the red population increased over time such that very few green-staining cells were observed, consistent with the significant damage of bacteria residing in the treated biofilm. After a 60-min incubation

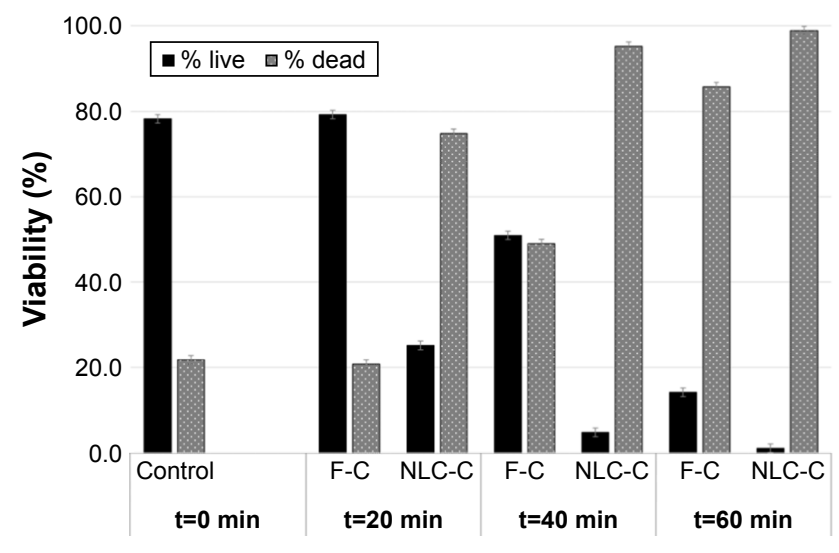

Figure I Graphical representation of living and dead bacteria treated or not treated with the different colistin formulations.

Note: Error bars represent the standard deviation of the mean (time: 0, 20, 40, and $60 \mathrm{~min}$ ).

Abbreviations: F-C, free colistin; NLC-C, colistin nanoparticulated in nanostructured lipid carrier.

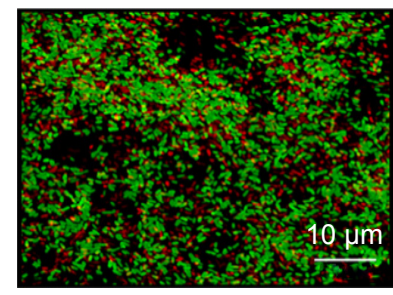

\section{Control}

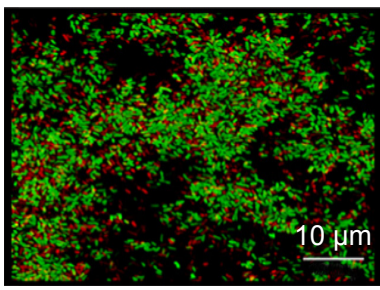

20 min free-col

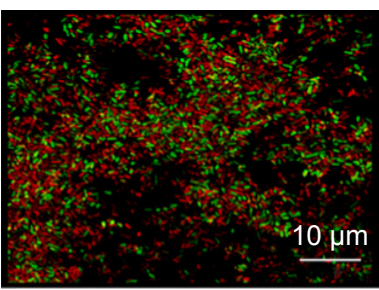

$40 \mathrm{~min}$ free-col

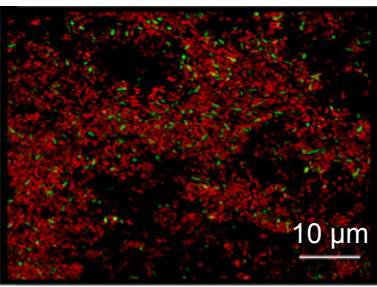

$60 \mathrm{~min}$ free-col

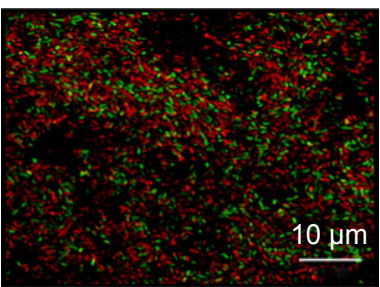

$20 \min$ NLC-col

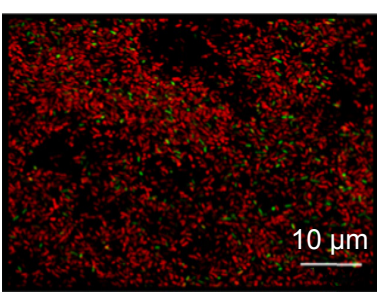

$40 \mathrm{~min}$ NLC-col

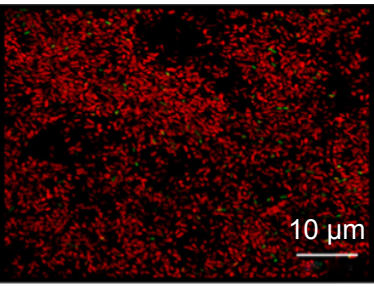

$60 \mathrm{~min}$ NLC-col
Figure 2 Confocal laser scanning microscopy images of Pseudomonas aeruginosa strain PAOI biofilms.

Notes: Control: untreated biofilm. Drug exposure time: 20, 40, and $60 \mathrm{~min}$. Green: viable bacteria; red: dead bacteria.

Abbreviations: free-col, free colistin; NLC-col, colistin nanoparticulated in nanostructured lipid carrier.

with NLC-colistin, all bacterial cells stained red. In the biofilms treated with free colistin (Figure 2), the percentages of the red and green populations of bacteria after $20 \mathrm{~min}$ were almost identical to those of the control. After 40 and $60 \mathrm{~min}$ (Figure 2), the red population in the free colistin treatment was always smaller than that in the NLC-colistin treatment, evidence of the faster killing of bacterial biofilms by the latter. This may reflect the ability of the lipid nanoparticles to easily penetrate the biofilm matrix, with the nanoparticulated drug then reaching the bacteria faster and more easily than free colistin..$^{21,22}$ Islan et $\mathrm{l}^{22}$ reported similar results using levofloxacin-loaded lipid nanoparticles. In that study, rapid killing of $P$. aeruginosa biofilms by NLC-levofloxacin was achieved after $60 \mathrm{~min}$ of exposure. 
Table I Percentage of the bacterial population living in the various layers and percentages of live and dead bacteria of the Pseudomonas aeruginosa strain PAOI biofilm after 20, 40, and 60 min of treatment with F-C and NLC-C

\begin{tabular}{|c|c|c|c|c|c|c|c|c|c|c|c|c|c|}
\hline \multirow[t]{3}{*}{ Treatment } & \multirow{3}{*}{$\begin{array}{l}\text { Biofilm } \\
\text { layer }\end{array}$} & \multicolumn{12}{|c|}{ Percentage of the bacterial population (\%) } \\
\hline & & \multicolumn{3}{|c|}{$\mathrm{t}=\mathbf{0} \mathrm{min}$} & \multicolumn{3}{|c|}{$t=20 \mathrm{~min}$} & \multicolumn{3}{|c|}{$\mathrm{t}=\mathbf{4 0} \mathrm{min}$} & \multicolumn{3}{|c|}{$\mathrm{t}=60 \mathrm{~min}$} \\
\hline & & Total & Live & Dead & Total & Live & Dead & Total & Live & Dead & Total & Live & Dead \\
\hline \multirow[t]{2}{*}{$\mathrm{C}+$} & Outer & 28.5 & 22.5 & 6.1 & & & & & & & & & \\
\hline & Inner & 71.5 & 55.8 & 15.7 & & & & & & & & & \\
\hline \multirow[t]{2}{*}{$\mathrm{F}-\mathrm{C}$} & Outer & & & & 32.4 & 29.0 & 3.4 & 35.2 & 20.9 & 14.3 & 37.9 & 6.6 & 31.3 \\
\hline & Inner & & & & 60.3 & 50.3 & 9.9 & 64.8 & 30.1 & 34.8 & 62.1 & 7.6 & 54.5 \\
\hline \multirow[t]{2}{*}{ NLC-C } & Outer & & & & 20.8 & 5.5 & 15.3 & 17.4 & 0.9 & 16.5 & 19.6 & 0.2 & 19.5 \\
\hline & Inner & & & & 79.2 & 19.7 & 59.6 & 82.6 & 3.9 & 78.7 & 80.4 & 0.9 & 79.5 \\
\hline
\end{tabular}

Abbreviations: $\mathrm{C}+$, untreated biofilm; F-C, free colistin; NLC-C, colistin nanoparticulated in nanostructured lipid carrier.

\section{Differentiation of distinct bacterial subpopulations in the strain PAOI biofilm}

Biofilms are a complex, multicellular structure that favors the generation of physiologically distinct subpopulations of bacteria that together form a community able to adapt to rapidly changing environmental conditions. ${ }^{23}$ To explore whether free and nanoencapsulated colistin differentially act on the subpopulations residing within the biofilm, the viability of bacteria in the different layers of the biofilm was determined. As seen in Table 1, the bacterial density was much higher in the inner layers of the biofilm, consistent with the previously reported high density of cells located close to the substratum in P. aeruginosa biofilms. ${ }^{24}$ The biofilms were investigated in greater detail by dividing them in half, which revealed that $71 \%$ of the total number of cells occupied the inner layers (Table 1). This was essentially the case in all three types of biofilms (control, free colistin, and NLC-colistin) despite the demonstrated heterogeneity among biofilms with respect to their thickness and the strength of their surface attachment. ${ }^{25}$ Nonetheless, our results can be explained by the initiation of cell detachment in the upper layers of the biofilm ${ }^{26}$ as well as the accumulation of high densities of smaller cells in deeper parts of the biofilm in response to external stress conditions. Also, it is likely that the washing step with buffer altered the external parts of the biofilm while leaving its deeper parts relatively undisturbed. Although weakly attached bacteria will be discarded by carefully washing the biofilms after $24 \mathrm{~h}$ of incubation, simultaneous disruption of the superficial layers of the biofilm is difficult to avoid.

The two colistin formulations did not differ in their effects on the various biofilm subpopulations, as the percentages of living and dead cells were higher in the inner than in the outer layers of biofilms treated with free colistin or NLC-colistin (Table 1). Our results demonstrate that both formulations are able to penetrate the deeper layers of the biofilm and thus access a dormant and anaerobically growing subpopulation. ${ }^{27,28}$ A reduction of the free colistin concentration, the delayed penetration of the free drug into the deeper portions of the multilayered biofilm, and the lack of specificity of NLC-colistin in killing metabolically active bacteria versus starved cells may account for our results, as proposed in similar studies. ${ }^{17,29}$ Further experiments will be aimed at improving the experimental conditions to optimize the performance of NLC-colistin.

\section{Conclusion}

In our previous works, ${ }^{16,18}$ we demonstrated the identical antimicrobial activity of free colistin and NLC-colistin. Here we have shown that NLC-colistin was clearly more effective than its free form in eradicating biofilms of $P$. aeruginos $a$, the most relevant pathogen in CF patients. Thus, the use of lipid nanoparticles may be an interesting strategy to prevent the growth and development of microbial biofilms in the clinical setting. NLC-colistin was much faster than free colistin in killing $P$. aeruginosa, based on the ability of the encapsulated drug to reach both the superficial and the deep regions of the biofilm. Further experiments are needed to identify the precise mechanism underlying the efficient removal of biofilms by NLC-colistin.

\section{Acknowledgments}

We thank Wendy Ran for copy editing the English version of the manuscript. This work was carried out under the Comprehensive Research on Effective Therapies for the Treatment of Cystic Fibrosis and Associated Diseases (IPT-20111402-900000) funded by the Spanish Ministry of Economy and Competitiveness. The authors gratefully acknowledge the support of the Scientific and Technological Centers (University of Barcelona, Bellvitge Campus, L'Hospitalet de LLobregat, Spain) and particularly the technical assistance of Dr Benjamin Torrejón in the CLSM study. MV is a member of the ENABLE (European Gram Negative Antibacterial Engine) European consortium (IMI-ND4BB). 


\section{Disclosure}

The authors report no conflicts of interest in this work.

\section{References}

1. Lyczak JB, Cannon CL, Pier GB. Lung infections associated with cystic fibrosis lung infections associated with cystic fibrosis. Clin Microbiol Rev. 2002;15(2):194-222.

2. Drenkard E, Ausubel FM. Pseudomonas biofilm formation and antibiotic resistance are linked to phenotypic variation. Nature. 2002; 416(6882):740-743.

3. Machineni L, Rajapantul A, Nandamuri V, et al. Influence of nutrient availability and quorum sensing on the formation of metabolically inactive microcolonies within structurally heterogeneous bacterial biofilms: an individual-based 3D cellular automata model. Bull Math Biol. 2017;79(3):594-618.

4. Taylor PK, Yeung AT, Hancock RE. Antibiotic resistance in Pseudomonas aeruginosa biofilms: towards the development of novel anti-biofilm therapies. J Biotechnol. 2014;191:121-130.

5. Hancock REW, Sahl HG. Antimicrobial and host-defense peptides as new anti-infective therapeutic strategies. Nat Biotechnol. 2006; 24(12):1551-1557.

6. Hancock RE. Cationic peptides: effectors in innate immunity and novel antimicrobials. Lancet Infect Dis. 2001;1(3):156-164.

7. Haney EF, Mansour SC, Hancock RE. Antimicrobial peptides: an introduction. Methods Mol Biol. 2017;1548:3-22.

8. Li J, Nation RL, Milne RW, et al. Evaluation of colistin as an agent against multi-resistant Gram-negative bacteria. Int J Antimicrob Agents. 2005;25(1):11-25.

9. Döring G, Flume P, Heijerman H, Elborn JS; Consensus Study Group. Treatment of lung infection in patients with cystic fibrosis: Current and future strategies. J Cyst Fibros. 2012;11(6):461-479.

10. Gales AC, Jones RN, Sader HS. Contemporary activity of colistin and polymyxin B against a worldwide collection of Gram-negative pathogens: Results from the SENTRY antimicrobial surveillance program (2006-2009). J Antimicrob Chemother. 2011;66(9):2070-2074.

11. Carmeli Y, Troillet N, Eliopoulos GM, Samore MH. Emergence of antibiotic-resistant Pseudomonas aeruginosa: comparison of risks associated with different antipseudomonal agents. Antimicrob Agents Chemother. 1999;43(6):1379-1382.

12. Liu YY, Wang Y, Walsh TR, et al. Emergence of plasmid-mediated colistin resistance mechanism MCR-1 in animals and human beings in China: a microbiological and molecular biological study. Lancet Infect Dis. 2016;16(2):161-168.

13. Jeannot K, Bolard A, Plésiat P. Resistance to polymyxins in Gram-negative organisms. Int $J$ Antimicrob Agents. 2017;49(5): 526-535.

14. Cipolla D, Shekunov B, Blanchard J, Hickey A. Lipid-based carriers for pulmonary products: Preclinical development and case studies in humans. Adv Drug Deliv Rev. 2014;75:53-80.
15. Pelgrift RY, Friedman AJ. Nanotechnology as a therapeutic tool to combat microbial resistance. Adv Drug Deliv Rev. 2013;65(13-14): $1803-1815$.

16. Sans-Serramitjana E, Fusté E, Martínez-Garriga B, et al. Killing effect of nanoencapsulated colistin sulfate on Pseudomonas aeruginosa from cystic fibrosis patients. J Cyst Fibros. 2016;15(5):611-618.

17. Pamp SJ, Gjermansen M, Johansen HK, Tolker-Nielsen T. Tolerance to the antimicrobial peptide colistin in Pseudomonas aeruginosa biofilms is linked to metabolically active cells, and depends on the $p m r$ and mexAB-oprM genes. Mol Microbiol. 2008;68(1):223-240.

18. Pastor M, Moreno-sastre M, Esquisabel A, et al. Sodium colistimethate loaded lipid nanocarriers for the treatment of Pseudomonas aeruginosa infections associated with cystic fibrosis. Int J Pharm. 2014; 477(1-2):485-494.

19. Singh R, Monnappa AK, Hong S, Mitchell RJ, Jang J. Effects of carbon dioxide aerosols on the viability of Escherichia coli during biofilm dispersal. Sci Rep. 2015;5:13766.

20. Klodzińska SN, Priemel PA, Rades T, et al. Inhalable antimicrobials for treatment of bacterial biofilm-associated sinusitis in cystic fibrosis patients: challenges and drug delivery approaches. Int J Mol Sci. 2016; 17(10). pii: E1688

21. Nafee N, Husari A, Maurer CK, et al. Antibiotic-free nanotherapeutics: ultra-small, mucus-penetrating solid lipid nanoparticles enhance the pulmonary delivery and anti-virulence efficacy of novel quorum sensing inhibitors. J Control Release. 2014;192:131-140.

22. Islan GA, Tornello PC, Abraham GA, et al. Smart lipid nanoparticles containing levofloxacin and DNase for lung delivery. Design and characterization. Colloids Surfaces B Biointerfaces. 2016;143:168-176.

23. Moormeier DE, Bayles KW. Staphylococcus aureus biofilm: a complex developmental organism. Mol Microbiol. 2017;104(3):365-376.

24. Yang L, Nilsson M, Gjermansen M, Givskov M, Tolker-Nielsen T. Pyoverdine and PQS mediated subpopulation interactions involved in Pseudomonas aeruginosa biofilm formation. Mol Microbiol. 2009; 74(6):1380-1392.

25. Flemming HC, Wingender J, Szewzyk U, Steinberg P, Rice SA, Kjelleberg S. Biofilms: an emergent form of bacterial life. Nat Rev Microbiol. 2016;14(9):563-575.

26. Rollet C, Gal L, Guzzo J. Biofilm-detached cells, a transition from a sessile to a planktonic phenotype: a comparative study of adhesion and physiological characteristics in Pseudomonas aeruginosa. FEMS Microbiol Lett. 2009;290(2):135-142.

27. Kim J, Hahn JS, Franklin MJ, Stewart PS, Yoon J. Tolerance of dormant and active cells in Pseudomonas aeruginosa PA01 biofilm to antimicrobial agents. J Antimicrob Chemother. 2009;63(1):129-135.

28. Bjarnsholt T, Ciofu O, Molin S, Givskov M, Høiby N. Applying insights from biofilm biology to drug development - can a new approach be developed? Nat Rev Drug Discov. 2013;12(10):791-808.

29. Haagensen JAJ, Klausen M, Ernst RK, et al. Differentiation and distribution of colistin- and sodium dodecyl sulfate-tolerant cells in Pseudomonas aeruginosa biofilms. J Bacteriol. 2007;189(1):28-37.
International Journal of Nanomedicine

\section{Publish your work in this journal}

The International Journal of Nanomedicine is an international, peerreviewed journal focusing on the application of nanotechnology in diagnostics, therapeutics, and drug delivery systems throughout the biomedical field. This journal is indexed on PubMed Central, MedLine, CAS, SciSearch ${ }^{\circledR}$, Current Contents ${ }^{\circledR} /$ Clinical Medicine,

\section{Dovepress}

Journal Citation Reports/Science Edition, EMBase, Scopus and the Elsevier Bibliographic databases. The manuscript management system is completely online and includes a very quick and fair peer-review system, which is all easy to use. Visit http://www.dovepress.com/ testimonials.php to read real quotes from published authors. 